\title{
DA PSEUDOCIÊNCIA PARANÓICA À CIÊNCIA DA PARANÓIA*
}

Luis Fernando Barnetche Barth, Maria Nestrovsky Folberg

Luís Fernando
Barnetche Barth
Psicanalista
e psicólogo;
doutorando em
Psicologia do
Desenvolvimento
pela Universidade
Federal do Rio
Grande do Sul
(UFRGS).
Maria Nestrovsky
Folberg
Psicanalista; docente
do Programa de
Pós-graduação
em Educação da
Universidade
Federal do
Rio Grande do
Sul (UFRGS);
coordenadora
do Núcleo de
Estudos e Pesquisa
em Psicanálise e
Educação (Neppe).

Luís Fernando

Barnetche Barth

Psicanalista

e psicólogo

doutorando em

Psicologia do

Desenvolvimento

pela Universidade

ral do Rio

Grande do Sul

Folberg

Psicanalista; docente

do Programa de

Pós-graduação

em Educação da

Universidade

Federal do

Rio Grande do

Sul (UFRGS)

Estudos e Pesquisa

Educação (Neppe)
RESUMO: Antes mesmo de ter acesso às memórias do presidente Schreber, Freud buscava explicar metapsicologicamente a paranóia. Desenvolvido de forma ensaística, os autores deste artigo mostram como Schreber ofereceu seu conhecimento paranóico à ciência e como Freud teve de lidar com a paranóia no seio da comunidade psicanalítica, como atesta sua correspondência pessoal, lutando para não sucumbir, a exemplo de Fliess e Ferenczi, à tentação de uma teoria sexual delirante.

Palavras-chave: Caso Schreber, paranóia e ciência, comunidade psicanalítica.

ABSTRACT: From paranoid pseudo-science to the science of paranoia. Even before reading President Schreber's Memories, Freud was searching for a metapsychological explanation of paranoia. In this paper developed in essayistic form, the authors show us how Schreber offered his paranoid knowledge to science and how Freud had to struggle with paranoia in the bosom of the psychoanalytic society, as it certifies his personal correspondence, fighting in order not to surrender, as Fliess and Ferenczi, to the temptation of a delirious sexual theory.

Keywords: Schreber's case, paranoia and science, psychoanalytic society.

0 livro Memórias de um doente dos nervos, de Daniel Paul Schreber (1903/1984) certamente não teria chegado aos nossos dias — e ao nosso conhecimento — se não fosse por sua estreita ligação com a psicanálise e, em especial, com as formulações dadas por Sigmund Freud (1911/1973). Sempre que nos remetemos a Daniel Paul Schreber, usamos antes a

\footnotetext{
* Artigo retirado da tese de doutorado "Da figuração à transfiguração da fantasia na construção do caso: as ficções metapsicológicas", defendida pelo autor no Programa de Pós-graduação em Psicologia do Desenvolvimento da UFRGS, sob a orientação da co-autora.
} 
denominação 'presidente Schreber', tal qual ficou consagrado pela psicanálise. Santner (1997) afirma que o texto freudiano estabelecido a partir da leitura das memórias schreberianas está irremediavelmente vinculado à obra de Schreber pela força interpretativa emprestada por Freud. Destarte, sempre que tratamos do tema 'Schreber', estamos travando um diálogo com Freud e com o caso metapsicológico por ele elaborado.

Quanto à sua finalidade intrínseca, a obra Memórias ${ }^{1}$ pode ser considerada um clássico, ainda que não encontremos aí a prosa historicamente bem descrita de um memorialista ou a ficção bem concebida de um romancista. Não, definitivamente, Schreber não escreve suas memórias visando à honraria de um prêmio Goethe, o qual foi conferido a Freud, mas, antes, como o testemunho escrito de seu padecimento. Aqui, é importante destacar que só tomamos esse texto por um texto clássico pelo fato de FREUD (1911/1973) tê-lo alçado a tal condição.

A quem interessaria ler uma expressão tão viva do adoecimento mental de um ser humano que não fosse alguém preocupado pela área dos transtornos mentais e psíquicos? Mannoni (1994) comenta, em sua biografia de Freud, que: "As qualidades intelectuais e morais de Schreber, sua memória, sua lucidez, sua sinceridade absoluta fazem de seu livro o mais perfeito relato de que dispomos de uma paranóia" (p.146). Muito provavelmente seu livro chegou aos leitores alemães pelo inusitado de seu conteúdo e por tratar de pessoa ilustre, filho de alguém não menos ilustre e de reconhecida importância nos meios educacionais. ${ }^{2}$ Basta que se leia a obra de Schreber para constatar que se trata de um fiel relatório de toda sua constelação delirante.

Em um ensaio intitulado Schreber als Schreiber, ${ }^{3}$ Mannoni (1973) afirma não podermos rejeitar as Memórias por terem sido escritas por um louco, uma vez que a literatura conhece outros casos como esse. Todavia, tal gênero de escrita, assim como as narrativas de viagens, não constitui gênero literário. O interesse suscitado pela obra recai sobre as ricas descrições, terreno fértil para as teorias de psiquiatras e psicanalistas sobre a psicose paranóica.

\footnotetext{
${ }^{1} \mathrm{O}$ termo Denkwürdigkeiten, escolhido por Schreber para dar título à sua obra, mais do que 'memórias', designa feitos memoráveis, coisas dignas de serem lembradas.

${ }^{2}$ Sabemos que o pai de Schreber era um médico de nome Daniel Gottlob Moritz Schreber. Uma nota de rodapé do artigo de Freud (1911/1973) esclarece que em todas as edições alemãs o nome Gottlob é incorretamente grafado Gottlieb - Gottlieb significa 'Amadeus', enquanto Gottlob pode ser traduzido pela expressão 'Deus seja louvado!', elemento esse que, possivelmente, deu azo a sua constelação delirante. Segundo consta, o pai de Schreber foi o fundador de um tipo de ginástica calistênica — exercícios para a beleza e para a tonicidade física - na Alemanha, e que visava à educação harmoniosa dos jovens e à elevação dos padrões de saúde, exercendo grande influência em seu tempo, a ponto de ver sua memória eternizada nas Associações Schreber, na circulação de um periódico médico (Ginástica Médica de Salão) e na publicação de livros sobre pedagogia, ginástica e higiene.

${ }^{3}$ Schreber como escritor.
} 
O que se destaca na obra de Schreber é justamente a descrição minuciosa e corajosa de sua realidade em detrimento da transformação dessa realidade em experiência literária ou poética. Nesse sentido, vale repetir os objetivos do autor expressos no início do livro:

"Creio que seria valioso para a ciência e para o conhecimento de verdades religiosas possibilitar, ainda durante minha vida, quaisquer observações da parte de profissionais sobre meu corpo e meu destino pessoal. Diante desta ponderação, deve calar-se qualquer escrúpulo de ordem pessoal.” (SCHREBER, 1903/1984, p.25)

Na segunda série de suplementos colocada ao final da obra, Schreber reitera seus objetivos, conforme segue:

"Depois de tudo isto não me resta mais nada senão oferecer minha pessoa ao julgamento dos especialistas, como objeto de observação científica. Este convite é o principal objetivo que persigo com a publicação do meu trabalho. Na pior das hipóteses, resta-me esperar que um dia com a dissecção do meu cadáver, possam ser constatadas peculiaridades comprobatórias no meu sistema nervoso, dado que sua constatação em corpos vivos, conforme o que me foi dito, se acompanharia de dificuldades extraordinárias ou se revelaria completamente impossível.” (SCHREBER, 1903/1984, p.326, grifos do autor)

As duas citações anteriores chamam a atenção para a forte intenção de Schreber para com a ciência, o que ratifica a idéia de que não se encontra nas Memórias objetivo literário, senão de maneira fortuita. Melman (2006) destaca, com propriedade, que, ao iniciar o capítulo 13, Schreber descreve um mundo reconciliado. O mês de novembro de 1895 marca uma mudança na forma de prever o futuro e mostra-se como um capítulo importante da história de vida de Schreber. Ele diz: “Lembro-me ainda claramente desse momento; coincidiu com uma série de belos dias do fim de outono, quando em todas as manhãs havia densa névoa sobre o Elba” (2006, p.175).

Registrada nesse período, encontramos uma mudança subjetiva que se desenrola no sentido de o texto ganhar ares romanescos, diferindo da descrição pesada, mas sempre precisa, de seu processo de adoecimento. Com razão, Melman (2006) afirma ser essa a única passagem em que podemos reconhecer "o retorno de um possível jogo metafórico em uma cadeia inconsciente, abrindo, com a harmonia do sujeito em seu mundo, a ambigüidade do lugar onde ele é falado e significado" (p.323).

Logo em seguida, Schreber (1903/1984) dá sua explicação para essa mudança sentida. Segundo ele, os sinais de feminização — sinais estes que somente eram percebidos pelo paciente — mostravam-se ao mesmo tempo em que revelavam 
para ele sua finalidade nesse processo. A eclosão dos supostos atributos feminis produz um momento de parada, de relaxamento das condições delirantes mais opressoras. É a partir desse momento, no qual o paciente consegue melhor suportar as exigências da vida, que surge, ainda que num lampejo deveras fugaz, a capacidade de se entregar à metáfora.

Destarte, podemos afirmar que essa passagem das Memórias antes citada é o único trecho no qual percebemos o peso da pena do escritor Schreber sobre a pena do cientista Schreber. Isso corrobora nossa idéia de que os estritos objetivos de sua obra, aliados à condição psíquica do paciente, não favorecem possíveis arroubos literários. Schreber escreve suas memórias com o intuito de oferecêlas à ciência, colocando-se como a experiência viva dos desígnios de Deus, por acreditar, como mostraremos adiante, que sua obra se iguale às grandes obras escritas já concebidas pela humanidade. ${ }^{4}$ Tal objetivo é sustentado por uma autovalorização exagerada, uma megalomania, a qual sói acompanhar os transtornos paranóicos. A história clínica de Schreber mostra, ainda que tardiamente, sua identificação com a figura de Jesus Cristo.

O núcleo das fantasias místico-religiosas de Schreber é ser fecundado pelos raios divinos gerando uma nova humanidade. Isso, depois de sua transformação em mulher ao preço de um eviração, ou seja, da retração de seus órgãos sexuais externos para dentro do corpo com a conseqüente transformação em órgãos sexuais femininos.

À guisa de comparação, trazemos um exemplo consagrado da literatura. Em seu livro intitulado Orlando — sua obra mais famosa - Virginia Woolf (1882-1941) retrata a biografia fantástica de um nobre inglês chamado Orlando, nascido no século XVI, que se transforma em mulher e vive até os anos 20 do século passado. Nesse livro, o tema da transformação em mulher, tão caro a Schreber, é trazido como elemento literário original.

Utilizando-se da mudança de sexo de seu personagem principal, Woolf (1928/1978) trata de traçar um panorama da Inglaterra quanto às questões relativas aos costumes da época. Ainda que seja de conhecimento geral que sua delicada saúde psíquica a tenha levado ao suicídio, Orlando não é colocado no papel por representar a própria vida da escritora. Orlando 'nasce' da verve literária de Woolf, mas os dois jamais se confundem.

Retomando o curso depois dessa rápida digressão, destacamos a intenção expressa no recurso por ele impetrado, o qual assina 'dr. Schreber, presidente da Corte de Apelação, em afastamento'. Schreber (1903/1984) declara: “A certeza

\footnotetext{
${ }^{4}$ Neste artigo, não visamos discutir as diferenças entre discurso científico e discurso literário ou ficcional. Todavia, sugerimos a leitura do livro Metapsicologia freudiana: uma introdução (ASSOUN, 1996), no qual encontramos um capítulo inteiro dedicado ao problema da ficção em psicanálise.
} 
do meu conhecimento de Deus e a absoluta segurança de estar em contato direto com Deus e com milagres divinos se ergue altíssima, muito acima de toda e qualquer ciência humana" [grifos do autor] (p.369). Ainda assim, confessa não querer ser tomado por pretensioso, na medida que a revelação da verdadeira natureza das coisas divinas de forma superior a qualquer outro ser humano deu-se nele em conseqüência de um milagroso encadeamento de circunstâncias.

O processo de compreensão dos fenômenos supranaturais, afirma Schreber, foi acompanhado da perda da alegria de viver. Todavia, ao compreender o teor de tais fenômenos, os mesmos passaram a ser o ponto central de sua vida, e a serenidade de espírito passou a estar relacionada à revelação de Deus — em quase todos os instantes - através de seus milagres e em uma língua especial (uma espécie de alemão arcaico e cheio de eufemismos) designada por ele de 'língua fundamental' (Grundsprache). Tendo em vista esses aspectos, ele está seguro em afirmar:

“[...] isto explica também o valor incomparavelmente elevado que dou à publicação das minhas Memórias. Pois se por meio delas eu conseguir não apenas despertar consideráveis dúvidas nos outros, mas também me for dado lançar uma luz por detrás do escuro véu que oculta o Além dos olhos dos homens, então o meu trabalho poderá fazer parte das obras mais interessantes que já foram escritas desde que o mundo existe." (SCHREBER, 1903/1984, p.370)

Santner (1997) argumenta que, em última análise, é à teologia e à filosofia que Schreber oferece suas Memórias, ainda que a expressão de seu desejo seja ter seu corpo examinado por cientistas. Nós, por outro lado, afirmamos que a alma de Daniel Paul Schreber - alma verdadeiramente atormentada - é a alma de um cientista, com a singularidade de que, nele, cientista e experimento habitam o mesmo corpo e se relacionam de forma interdependente.

O corpo humano depende do discurso, da inscrição de significantes, para encontrar sua função adequada, ou seja, enquanto corpo simbólico. Já para Schreber, diferentemente de um paciente neurótico, seu corpo se mostra refratário à metáfora. Nesse caso, sem mediação simbólica, o real do corpo responde diretamente pela incidência do significante. O próprio corpo de Schreber faz as vezes do Outro.

Ao lermos atentamente o que Schreber assevera no final da segunda série de suplementos de sua obra - isto é, que, na pior das hipóteses, a dissecção de seu cadáver haveria de elucidar o que ele revelara com tamanha riqueza de detalhes - , chama a atenção o fato de ele chegar a admitir que, no fim, a ciência é que possa sobreviver à sua concepção escatológica. A ciência, para Schreber, deve ser entendida como uma ciência natural (Naturwissenschaft) que 
congregaria, de forma integrada e absoluta, todo o conhecimento instituído, incluindo-se nela os campos da neurologia, da religião e da filosofia, unificando todo o conhecimento existente. ${ }^{5}$ Sua obra luta contra a limitação das formas de conhecimento humano e expressa o voto de que a cosmogonia por ele revelada tenha um tratamento científico e encontre, no seu corpo, as provas empíricas dessa revelação.

Assim como Freud (1911/1973) fala de uma realização de desejo postergada ad infinitum, assintoticamente realizada, também é verdade que Schreber, antes de oferecer seu cadáver para dissecção futura, fala de um relógio carrilhão inutilizado pelo efeito dos milagres. Não há mais uma contagem cronológica do tempo, pois, "na pior das hipóteses” (SCHREBER, 1903/1984, p.326), ou seja, se o Götterdämmerung ${ }^{6}$ — como caracteriza o seu fim do mundo — não se realizar, haverá sempre o recurso do exame científico de seu sistema nervoso. É como se, no fundo, suspeitasse de suas previsões.

Lacan (1966/2003) conclui sua Apresentação das 'Memórias de um doente dos nervos' apontando para a importância do vínculo estabelecido entre o paciente e o clínico, no qual ao clínico é dado responder deste lugar de objeto, que, no caso Schreber, é o de uma espécie de erotomania mortificante. Para Lacan, a fotografia do dr. Flechsig diante da imagem de um cérebro encontrada na abertura da versão inglesa das Memórias mostra perfeitamente o sentido dado ao Sujeito Suposto Saber nessa transferência. Daí, Lacan conclui que tudo o que está em jogo nesse magnífico caso - ainda que a ascese mística e a abertura às vivências do paciente possam nos ofuscar — é tão-somente a lógica introduzida pelo tratamento.

A figura do dr. Flechsig aparece em destaque ao longo das Memórias. Aliás, sua obra mostra o supremo esforço de integrar elementos de suas experiências vividas em um todo coeso. É como se uma força centrípeta juntasse os elementos mais anódinos a outros de maior importância, de modo que nenhum deles fosse

\footnotetext{
${ }^{5}$ O modelo de ciência para Schreber é o da ciência natural do século XIX. Do mesmo modo, ASSOUN (1983) menciona que Freud escolheu definir a psicanálise como uma ciência natural, em detrimento de uma ciência do espírito (Geisteswissenschaft), porque Freud desconhecia outra forma de ciência. A cientificidade, para Freud, estava fortemente calcada nos modelos físico-químicos de sua época, de modo que ciência (Wissenschaft) e ciência natural (Naturwissenschaft) eram uma mesma e única coisa. Milner (1996) também esposa a idéia de que Freud se esforçava em conformar a psicanálise à ciência normal como testemunho da conquista do mundo moderno. Por outro lado, Milner destaca que o 'sonho da monografia botânica' mostra a renúncia de Freud à monografia como forma de expressão da ciência normal e a conseqüente preferência dada ao livro, por melhor representar a obra e a cultura. A Traumdeutung é o testemunho dessa escolha.

${ }^{6}$ Schreber utiliza-se do tema da ópera Crepúsculo dos deuses de Richard Wagner (1813-1883) - que faz parte da tetralogia do Anel dos Nibelungos - por aproximar-se do tema do livro 'Apocalipse', da Bíblia. Consta, em Santner (1997), que Heinrich Behr, sogro de Schreber, foi um cantor lírico e produtor de obras de Wagner.
} 
excluído de um grande sistema integrador. Nessa via, vemos, aqui e ali, brotarem expressões e personagens retiradas da literatura, entre outros.

Nessa tentativa de integração de diversos elementos ao seu sistema delirante e a primazia dada à figura de Flechsig, destacamos uma pequena nota de Santner (1997), segundo a qual Johann Andreas Rodig, um sapateiro de Leipzig, também lutou no mesmo tribunal onde Schreber exercera a atividade de juiz, contra uma sentença de interdição. Em um panfleto publicado pelo paciente, ele agradece ao Herr Professor Flechsig e ao Herr dr. Teuscher, por tratarem de seus nervos e por garantirem o seu juízo (p.198, nota 27). Possivelmente, esse fato ajudou Schreber a moldar expectativas favoráveis em relação a Flechsig. Santner afirma que Flechsig, como perito forense, era mais sensível aos interesses dos pacientes do que a maioria de seus colegas. Por isso, a decisão de transferir Schreber para o manicômio público de Sonnenstein teria sido sentida, segundo Santner, como uma traição.

Além de isso tudo reforçar a importância do dr. Flechsig - eminente neurologista - , podemos verificar a utilização do nome do outro médico em seu delírio. Schreber (1903/1984) fala de um dr. Täuscher, médico-assistente do professor Flechsig. Acontece que Täuscher significa, literalmente, 'enganador' e, por outro lado, é homófono a Teuscher. Também é oportuno lembrar a importância dada ao dr. Flechsig no seio da família Schreber. Consta que a esposa de Schreber manteve, por muitos anos, junto a sua escrivaninha, uma fotografia do dr. Flechsig por gratidão pela recuperação de seu marido. Nome reconhecido no mundo da neurologia, Flechsig ${ }^{7}$ não passou incólume à observação do jovem Freud. Além disso, segundo Santner (1997), os textos neurológicos de Freud contêm muitas referências ao trabalho de Flechsig, o que também se pode verificar no obituário que escreveu em homenagem a Charcot:

"Quando emergiram as duas grandes inovações — as experiências de estimulação de Hitzig-Fritsch e as descobertas de Flechsig sobre o desenvolvimento da medula espinhal - que anunciaram uma nova época no nosso conhecimento da 'localização das doenças nervosas', as lições de Charcot sobre esse assunto desempenharam o mais importante papel na aproximação das novas teorias com o trabalho clínico, tornando-as frutíferas para este.” (FREUD, 1893/1976, p.25)

\footnotetext{
${ }^{7}$ Quanto ao dr. Flechsig, deve-se a ele a descoberta da mielinização, em 1872, a partir da dissecção do cérebro de um menino de cinco semanas chamado Martin Luther, transformando essa descoberta na base de sua metodologia de pesquisa e de seu sistema neuroanatômico, estendendo-se também as suas concepções psiquiátricas. Flechsig foi o fundador do método ontogenético de análise da estrutura interna do sistema nervoso central, mostrando à ciência a importância da mielinização no desenvolvimento do sistema nervoso e sua importância na maturação de vários sistemas neurais.
} 
Voltando um pouco mais no tempo, encontramos uma referência a Flechsig em carta enviada por Freud (1873-1890/1972) a sua noiva Martha, datada de 4 de novembro de 1885, em que comenta o reencontro com o amigo médico russo L. O. Dark Schewitsch, que chegou a traduzir um artigo de Freud para uma revista russa e com o qual escreveria, em co-autoria, um artigo em 1886. Ao relatar a forma como conheceu Schewitsch e as atividades desenvolvidas no laboratório de Meynert, Freud diz: “(...) aborrecido com Meynert, partiu para Leipzig com meu rival Flechsig” (p.162, grifo nosso). É como rival que Freud se refere a Flechsig, colega de especialidade. Na época em que essa carta é trocada, Schreber e sua esposa estão em viagem de convalescença, após ele estar internado por seis meses na clínica para doenças nervosas da Universidade de Leipzig cujo diretor era Flechsig.

Dark Schewitsch, que também aparece grafado como Darkschewitsch, mais consoante à sua origem russa, pode ser o neurologista judeu mencionado por Schreber (1903/1984) em seu delírio como tendo um nome similar ao de um padre beneditino judeu batizado, que objetivava eslavizar a Alemanha e lançar as bases da dominação dos judeus através dele. Esse padre, cujo nome soava algo como 'Starkiewicz', liderou, em seu delírio, os 240 beneditinos que pereceram em sua cabeça.

Salientamos que, ainda que os primeiros trabalhos científicos de Freud tivessem sua relevância, ele jamais conseguiu conquistar, na área da neurologia, o mesmo prestígio do qual Flechsig gozava por suas descobertas. Então, a partir das referências a Flechsig encontradas na obra de Freud, podemos afirmar que a leitura feita por Freud das Memórias de Schreber marca também um reencontro de Freud com Flechsig, acarretando o que entendemos ser uma certa disputa entre a tentativa de cura oferecida pela concepção neurológica da paranóia e a oferecida pela explicação psicanalítica. Ainda que a obra de Schreber fosse publicada em 1903, com a conseqüente discussão nos meios psiquiátricos da época, o tema da paranóia só voltou a interessar Freud em 1910, quando de sua viagem com Ferenczi à Sicília. Antes disso, o Rascunho $\mathrm{H}$, anexado a uma carta a Fliess em 24 de janeiro de 1895 (MASSON, 1986), trata do mesmo tema, ainda que fosse uma etapa inicial de suas pesquisas.

O caso Schreber, ao que tudo indica, começou a ser pensado durante essa viagem. Em 24 de setembro de 1910, ainda em Roma, pouco antes de partir de viagem de volta ao lar, Freud escrevera a primeira parte de uma carta a Jung (carta 212F) contando sobre a viagem e fazendo alguns comentários sobre Ferenczi, seu companheiro de viagem. Segundo Freud, Ferenczi mostrara-se infantil, passivo e receptivo demais, como uma mulher, a ponto de Freud afirmar que sua homossexualidade não ia longe o bastante para aceitá-lo dessa forma. Logo em seguida, no mesmo parágrafo, Freud muda de assunto e assevera: "Diferen- 
tes noções científicas que eu trouxera comigo combinaram-se para dar forma a um texto sobre paranóia que pede ainda uma conclusão, mas que significa um grande avanço para explicar o mecanismo da escolha da neurose" (MCGUIRE, 1993, p.367).

Freud (FALZEDER, BRABANT \& GIAMPIERI, 1994) não deixa de expor seus sentimentos para o próprio Ferenczi em uma carta (169F) datada de 2 de outubro de 1910, em que menciona o aspecto infantil do jovem. Ferenczi também prepara uma longa carta a Freud (170Fer), sem que tivesse recebido a que continha as impressões de Freud, ao que tudo indica, porque a data é de 3 de outubro de 1910. Nela, ele esclarece as impressões desagradáveis despertadas durante essa viagem, as quais estavam ligadas à falta de reciprocidade na relação com o pai da psicanálise, na busca de um entendimento psicanalítico. Comenta ter-se dado conta da resistência contra seus próprios componentes homossexuais, o que promoveu um proveito pessoal e científico, e afirma compreender a dificuldade de Freud em se mostrar sem reservas após o que chamou de 'caso Fliess'. Ainda na mesma correspondência, Ferenczi faz um importante comentário:

"O senhor me disse certa vez que a $\Psi \alpha$ seria somente uma ciência de fatos, de indicadores, que não deveriam ser traduzidos para o plano interpretativo, pois este último seria paranóico. Segundo esta concepção, não haveria uma visão de mundo $\psi \alpha$, nem uma ética $\psi \alpha$, nem normas de conduta $\psi \alpha$. Eu também não conheço outra regra ética além da ética da razão pura. Mas a ampliação e expansão da razão a regiões até então inconscientes tem uma influência muito significativa, também para o não-paranóico, sobre a visão de mundo e o modo de agir.” (FALZEDER, BRABANT \& GIAMPIERI, 1994, p.278-279)

Ferenczi afirma não querer reformar a sociedade, porque não é paranóico, mas espera que seja estabelecida uma relação mais desinibida entre dois homens de orientação psicanalítica, na qual tanto os pensamentos quanto a fala tivessem livre expressão. Todavia, espera que o processo de aproximação inicie por Freud, pois, como afirma: “Infelizmente eu não posso começar: o senhor é que deve! O senhor é a $\Psi \alpha$ em pessoa!” (FALZEDER, BRABANT \& GIAMPIERI, 1994, p.279).

Queremos destacar a resposta dada a esta carta de Ferenczi. Freud (carta 171F) defende-se, dizendo não ser o super-homem (Übermensch) psicanalítico construído e que não superara a contratransferência - 15 anos antes, Ferenczi analisara-se com Freud durante três semanas. O inventor da psicanálise assevera então:

“Não só o senhor percebeu que eu não mais possuo necessidade daquela abertura total da personalidade, mas também compreendeu, retomando corretamente à 
causa dessa situação. Portanto, por que o senhor teimou nisso? Desde o caso Fliess, durante a superação do qual o senhor justamente me viu ocupado, essa necessidade exauriu-se em mim. Uma parte de investimento homossexual foi retirada e empregada na ampliação de meu próprio Eu. Tive sucesso onde o paranóico fracassa." (FALZEDER, BRABANT \& GIAMPIERI, 1994, p.281, grifo nosso)

Freud traz ainda alguns argumentos sobre o comportamento desagradável de seu companheiro de viagem, para, ao final da mesma carta, fazer referência ao caso Schreber:

"Certamente não escrevi que trabalhei no caso Schreber, encontrando a confirmação para o núcleo de nossas suposições sobre a paranóia e que aproveitei todas as oportunidades para fazer sérias interpretações. Agora pedi a Stegmann que descubra detalhes pessoais do velho Schreber. Está dependendo desses relatórios o que irei dizer publicamente sobre o assunto. O que o senhor acha de o velho dr. Schreber ter feito 'milagres' como médico, mas que, de resto, era um tirano em casa, 'urrava' com o filho, e o compreendia tão pouco quanto o 'deus inferior' compreendia o nosso paranóico? Aceitam-se de bom grado contribuições para a interpretação do caso Schreber.” (FALZEDER, BRABANT \& GIAMPIERI, 1994, p.281-282)

Aqui, o tema 'Schreber' já se mostra em franco processo de elaboração, no qual se destaca a tentativa de integração do material delirante do paciente à luz de uma concepção teórica propriamente psicanalítica. Todavia, Freud assume aguardar por informações factuais de Stegmann ${ }^{8}$ sobre o pai do presidente Schreber. Ainda que afirme não se ter utilizado de nenhum dado além dos oferecidos pelo próprio texto das Memórias, com exceção da idade de Schreber à época de sua doença, como Freud (1911/1973) chega a afirmar (p.65, nota1), é provável que outros dados viessem a compor o seu ensaio, como sugerido por ele mesmo em uma carta à princesa Marie Bonaparte (p.137, nota 2).

Nessas trocas de correspondências, o que chama a atenção é a Stimmung que paira sobre essas relações, concorrendo no aparecimento do trabalho freudiano sobre o presidente Schreber. Destacamos como elementos em jogo: primeiro, as dificuldades na relação Freud-Ferenczi, à sombra do que fora a relação Freud-Fliess, principalmente quanto aos aspectos homossexuais presentes nessas relações, os quais encontrarão uma explicação teórica na própria elucidação do caso Schreber; segundo, o espectro da paranóia a rondar essas relações como um traço presente na formação da comunidade científica dos primeiros psicanalistas;

\footnotetext{
${ }^{8}$ Arnold Georg Stegmann, psiquiatra de Dresden (cidade de Schreber), tornou-se sóciofundador da Sociedade de Berlim.
} 
terceiro, a tentativa do discurso paranóico de se assemelhar a um conhecimento cientificamente demonstrado; e, por fim, a ligação de um antigo rival (Flechsig) com o relato do tratamento malogrado de Schreber.

Ainda encontramos nas cartas trocadas entre Freud e Ferenczi confidências que localizam o problema da paranóia no seio da comunidade psicanalítica. Em 16 de dezembro de 1910 (carta 188F), Freud escreve ao jovem colega, dizendo: "Atualmente, superei o caso Fliess, sobre o qual o senhor estava tão curioso. Adler é um pequeno Fliess redivivo, igualmente paranóico. Steckel, como seu apêndice, no mínimo tem o nome de Wilhelm" (FALZEDER, BRABANT \& GIAMPIERI, 1994, p.301), fazendo referência ao prenome de Fliess.

A relação entre o caso Schreber e o seu ex-amigo Fliess é ratificada quando da conclusão de seu trabalho. Freud (MCGUIRE, 1993) escreve a Jung dois dias mais tarde (carta 225F, de 18/12/1910), dizendo ter concluído 'seu' Schreber e que só lhe falta um prefácio como complemento. $O$ autor não se sente totalmente satisfeito com seu produto e afirma ter lutado, ao escrevê-lo, com complexos ligados a Fliess, os quais o perturbavam.

Freud (1911/1973) acredita encontrar no texto schreberiano um campo aberto à investigação pela falta de segredo - o contrário do que se espera em uma estrutura neurótica — , ainda que o material sofra certa distorção. A figuração produzida por Schreber é descrita de maneira tão vívida e tão alheia às defesas que tanto nos concernem, que se tornam um campo verdadeiramente fértil para o trabalho do analista. Assim, Freud não chega a conhecer pessoalmente o paciente, o qual morre pouco depois da publicação do ensaio freudiano. Isso quer dizer que ele não se preocupou em demasia com os dados factuais, mesmo que haja indicação de que recebera informações do dr. Stegmann sobre a família Schreber.

Na medida que Freud (1911/1973) se baseia no material apresentado pelo próprio doente e busca, por meio do recurso da narratividade, oferecer um modelo explicativo crível para a paranóia, os dados da história do paciente devem ser examinados de maneira crítica. Dessa forma, Freud consegue estabelecer outro entendimento em relação tanto à teoria pessoal de Schreber quanto à teoria psiquiátrica vigente à época, afirmando que o interesse da psiquiatria não vai além de determinar a presença do delírio e sua influência na vida do paciente. Já, para a psicanálise, o interesse recai sobre os motivos de tal transformação, aprofundando-se nas particularidades ou nos pormenores do delírio e na história de seu desenvolvimento. Freud apresenta, então, uma terceira posição em relação àquelas duas, marcando a interpretação psicanalítica como diferente.

Destarte, o 'caso Schreber' não partiu do tratamento psicanalítico de um paciente, mas da leitura das Memórias produzidas por ele. Não foram as dificuldades do processo de cura de um paciente que levaram Freud a teorizar sobre o tema 
da paranóia. Ao contrário, Freud parte da problemática que envolve o tema da paranóia, indo ao encontro de uma história clínica que a ratifique. Na tessitura do arcabouço teórico da paranóia, principalmente no que se refere aos componentes homossexuais, Freud apóia suas elaborações em suas próprias vivências. É nessa perspectiva que ele vai buscar, no livro de Schreber, elementos para suas intuições teóricas. Quando conclui a tradução de um artigo de Putnam, escreve a Jung dizendo (carta 214F, de 1\%/10/1910):

"Esse trabalho interrompeu meu estudo de Schreber, que agora devo retomar. $\mathrm{Na}$ Sicília eu não passei da metade do livro, mas o mistério já ficava claro. A redução ao complexo nuclear é fácil. [...] Para a felicidade da psiquiatria esse pai era também - médico. Comprova-se pois, mais uma vez, o que notamos em tantos casos paranóides quando estive em Zurique, a saber, a impossibilidade de evitar a recatexia das próprias inclinações homossexuais em que os paranóicos se encontram. Com isso o caso se enquadra em nossa teoria. Vejo que o senhor anda a encarar o trabalho como eu, deixando o caminho óbvio para seguir sua própria intuição. Este é, a meu ver, o procedimento mais correto; para nosso grande espanto, todas as voltas que damos revelam-se mais tarde absolutamente lógicas." (MCGUIRE, 1993, p.371-372)

A correspondência freudiana, sem dúvida nenhuma, é um excelente material para a pesquisa psicanalítica. Nela, encontramos, por meio da elaboração dada a diversos temas, o gérmen de suas teorias. Freud lança uma hipótese, a qual busca contrastar com os exemplos clínicos de que dispõe e, no caso de Schreber, vai buscar uma história clínica que possa servir de pano de fundo, de contextualização de suas intuições teóricas. Na mesma carta a Jung (carta 214F) citada antes, Freud complementa:

“Durante a viagem fiz algum progresso nessa teoria, o qual pretendo agora pôr à prova contra o histórico clínico de Schreber e várias outras publicações sobre a paranóia. Comparada às intenções, a coisa está porém tão incompleta que não sei quando a poderei publicar nem que extensão virei a dar-lhe. É provável que se converta num estudo sobre Schreber e muita gente há de achar que eu extraí toda a teoria do livro." (MCGUIRE, 1993, p.371)

Sabe-se que o problema da paranóia inquietava Freud já há algum tempo; e estivera presente em sua relação com Fliess. Por isso, não nos furtaremos a mais uma referência a suas cartas. Em 1908, em correspondência datada de 18 de fevereiro (carta 70F), Freud afirma a Jung: 
"Meu ex-amigo Fliess desenvolveu uma paranóia horrível depois de se livrar da afeição por mim, que era sem dúvida considerável. Devo esta idéia a ele, i. e., ao comportamento dele. O desajuste das sublimações na paranóia entra no mesmo contexto. Não são poucas, ao todo, as idéias incipientes e incompletas que tenho para lhe expor." (MCGUIRE, 1993, p.153)

Sabemos, através dos dados que a história nos legou, que, além de Daniel Paul Schreber, também Fliess e Ferenczi sucumbiram à paranóia. De fato, na origem da psicanálise, encontramos a luta de Freud para impor suas idéias e manter sua orientação diante das teorias desviantes que tentavam conceber uma “ciência sexual” paranóica a partir de um discurso pseudocientífico. Fliess é um exemplo patente disso, com a elaboração de sua teoria orgânica, a qual poderia perfeitamente se integrar ao livro de Schreber, e que concebia ciclos periódicos de descarga por vias normal ou substitutiva de um fluxo. Tendo como marco a regulação do mundo pela menstruação, isto é, pela periodicidade, Fliess desloca para o nariz - ele que era rinolaringologista — o órgão privilegiado para dar vazão a essa descarga, estendendo, mais tarde, a periodicidade para os homens, os animais e as plantas, na qualidade de uma verdadeira lei natural.

André (1987) mostra com propriedade como Fliess transforma seu nome em um princípio universal. Em alemão, o verbo fliessen tem o sentido de fluir e "das fliess" quer dizer "isso flui" ou, simplesmente, "flui”, na medida que, na língua alemã, ao contrário de na portuguesa, não existe a possibilidade de uma oração sem sujeito. Freud consegue desvencilhar-se da sedução da teoria científicoparanóica do dr. "Flui", ainda que não consiga impedir as influências deste no seio do movimento psicanalítico. Karl Abraham, por exemplo, sucumbe à tentação e se entrega a um tratamento com Fliess alguns meses antes de falecer, vítima de tuberculose. Todavia, Abraham acreditava que sua doença confirmava as idéias fliessianas de periodicidade.

Quinet (2006) afirma que a certeza delirante somada ao fato de, normalmente, o paranóico confundir-se com o ideal que representa torna o lugar de mestre especial para ele, cuja estrutura é messiânica. Se o mesmo tiver o poder de persuasão, reunirá pessoas em torno de si a partir de seu delírio, o que explica as influências de Fliess entre os discípulos de Freud.

Outro a sucumbir à paranóia foi Ferenczi. Segundo Jones (1979), a saúde mental de Ferenczi mostrava-se conturbada já no início de 1930 e se agravaria até sua morte, em 1933, mas uma conversa com Freud naquele ano pareceu ter apaziguado as divergências ocultadas durante anos, principalmente quanto às queixas de Ferenczi sobre a unilateralidade nas relações dele com Freud. Aquele a quem Freud muitas vezes chamara de filho nutria divergências teóricas inconfessas. Nas palavras de Jones: 
“A última carta de Ferenczi, escrita da cama em 4 de maio, eram umas poucas linhas para assinalar o aniversário de Freud. A perturbação mental vinha fazendo progressos rápidos nos últimos meses. Relatava ele como uma sua paciente americana, a quem costumava devotar quatro ou cinco horas diárias, o havia analisado e dessa maneira o pusera curado de todas as suas afecções. Através do Atlântico vinham mensagens da paciente a ele - Ferenczi fora sempre um firme crente na telepatia. Em seguida enumerava as decepções acerca da suposta hostilidade revelada por Freud. Já no fim de sua vida, ocorreram violentos ataques paranóicos e mesmo homicidas, a que se seguiu a morte repentina, a 24 de maio.” (p.728-729)

Como indicamos, a construção teórica do edifício psicanalítico e o conseqüente convívio dos psicanalistas com seus pares no seio da nova comunidade que formaram revelam um entrelaçamento de relações transferenciais e contratranferenciais nem sempre devidamente trabalhadas. A correspondência de Freud mostra como os elementos ligados ao entendimento da paranóia necessitaram, antes de mais nada, ser compreendidos no âmago das relações estabelecidas com seus colegas e discípulos, na qualidade de alteridades para a construção de sua psicanálise. Freud resistiu à sedução paranóica, arrancando-a de suas relações - sobretudo, no início, no que diz respeito à figura e à importância de Fliess em sua vida, seguida, também, pela interlocução com Ferenczi —, para transformá-la em teoria. Destarte, Freud rejeita a concepção paranóica da psicanálise ao conceber a teoria psicanalítica da paranóia.

Nesse sentido, podemos afirmar que, se Freud tem êxito onde os paranóicos fracassam, isso se deve menos à capacidade de reinvestimento das pulsões homossexuais do que ao fato de ter concebido uma teoria científica da paranóia, ou seja, uma teoria da paranóia dentro de um discurso científico sem se deixar cair na armadilha das concepções pseudocientíficas comumente elaboradas nos delírios paranóicos. Salientamos que a paranóia de Schreber - sua teoria, sua cosmogonia — não foi absorvida ainda que oferecida à ciência, pois, apesar de apresentadas na forma de um conhecimento novo, não deixaram de ser a expressão de um conhecimento paranóico, isto é, relativo "ao conhecimento imaginário projetivo característico do eu consciente” (QUINET, 2006). O rigor da apresentação das idéias no delírio paranóico, sua concatenação lógica, faz com que o conhecimento paranóico se pareça com um conhecimento cientificamente demonstrado. Compreende-se, então, por que Freud (1911/1973) conclui seu ensaio afirmando que o futuro há de mostrar se há mais delírio do que gostaria de admitir em sua teoria ou mais verdade no delírio de Schreber.

A importância do caso Schreber é capital por mostrar esse momento de articulação teórica. Ao redigir o seu ensaio Notas psicanalíticas sobre um relato autobiográfico de um caso de paranóia (Dementia paranoides), como foi traduzido para o português, 
Freud resolve sua relação transferencial com Fliess, oferecendo uma teoria científica da paranóia. Por outro lado, a neurologia de Flechsig, com quem Freud já rivalizara, também se mostrava inadequada ou insuficiente no tratamento do presidente Schreber, como as Memórias tornaram patente: "talvez não se possa exigir do diretor de uma grande instituição, na qual se encontram centenas de pacientes, que ele penetre profunda e detalhadamente na conformação mental de um único deles" (SCHREBER, 1903/1984, p.59).

Destarte, os elementos em jogo na concepção do caso Schreber de Freud - e basta lembrar que ele se referira ao caso como sendo o 'meu' Schreber — não são completamente conscientes para ele ao escrever. As transferências em jogo, verdadeiro pano de fundo da obra produzida, podem ser tomadas como o contexto sobre o qual Freud tece sua teoria. Nesse sentido, cabe ressaltar, além das dificuldades no relacionamento com Ferenczi já comentadas, a proximidade com Jung e a consideração a algumas de suas idéias — o que fica patente no pósescrito, sem falar na ainda presente influência de Fliess, na medida que vemos Freud recorrer aos ciclos fliessianos na idéia de um climatério masculino, dando respaldo à sua argumentação.

Ao dar uma nova explicação para a formação delirante, Freud (1911/1973) marca uma diferença em relação ao entendimento psiquiátrico, cumprindo com o objetivo esboçado no início de seu artigo. Ao final, ele, que não teve receio de aceitar o desafio de Schreber de uma investigação científica da loucura, espera ter triunfado sobre o delírio. Esse ponto mostra que, se Freud teme ser acusado de conceber uma teoria delirante, é porque suas explicações não deixam de se dar no terreno da ficção. Para tornar inteligível o phantasieren do paciente, Freud oferece uma ficção metapsicológica, ou seja, uma construção na qual os elementos em jogo ganharão nova imagem teórica metapsicológica.

Recebido em 14/3/2007. Aprovado em 24/7/2007.

\section{REFERÊNCIAS}

ANDRÉ, S. (1987) O que quer uma mulher? Rio de Janeiro: Jorge Zahar. ASSOUN, P.-L. (1983) Introdução à epistemologia freudiana. Rio de Janeiro: Imago. (1996) Metapsicologia freudiana: uma introdução. Rio de Janeiro: Imago.

FALZEDER, E., BRABANT, E. \& GIAMPIERE, P. (1994) Sigmund Freud \& Sándor Ferenczi: correspondência (1908-1911). v.1. Rio de Janeiro: Imago. 
FREUD, S. (1873-1890/1972) Epistolário I. Barcelona: Plaza \& Janés. . (1911/1973) Studienausgabe, Frankfurt am Main, S. Fischer. "Psychoanalytische Bemerkungen über einen autobiographisch beschriebenen Fall von Paranoia (Dementia paranoides)", v.7, p.133-203.

. (1893/1976) Edição standard brasileira das obras completas de Sigmund Freud, Rio de Janeiro: Imago. "Charcot”, v. 3, p.19-34.

JONES, E. (1979) Vida e obra de Sigmund Freud. Rio de Janeiro: Guanabara.

LACAN, J. (1966/2003) “Apresentação das memórias de um doente dos nervos”, in Outros escritos. Rio de Janeiro: Jorge Zahar.

MANNONI, O. (1973) Chaves para o imaginário. Petrópolis: Vozes.

. (1994) Freud: uma biografia ilustrada. Rio de Janeiro: Jorge Zahar.

MASSON, J. M. (1986) A correspondência completa de Sigmund Freud para Wilhelm Fliess - 1887-1904. Rio de Janeiro: Imago.

MCGUIRE, W. (1993) A correspondência completa de Sigmund Freud e Carl G. Jung. Rio de Janeiro: Imago.

MELMAN, C. (2006) Retorno a Schreber. Porto Alegre: CMC.

MILNER, J.-C. (1996) A obra clara: Lacan, a ciência, a filosofia. Rio de Janeiro: Jorge Zahar.

QUINET, A. (2006) Psicose e laço social: esquizofrenia, paranóia e esquizofrenia. Rio de Janeiro: Jorge Zahar.

SANTNER, E. L. (1997) A Alemanha de Schreber: uma história secreta da modernidade. Rio de Janeiro: Jorge Zahar.

SCHREBER, D. P. (1903/1984) Memórias de um doente dos nervos. Rio de Janeiro: Graal.

WOOLF, V. (1928/1978) Orlando. Rio de Janeiro: Nova Fronteira.

Luís Fernando Barnetche Barth

luisfernandobarth@terra.com.br

Maria Nestrovsky Folberg

m.folberg@terra.com.br 